\title{
Codificación clínica con la CIE9MC
}

\author{
M. S. Acedo Gutiérrez ${ }^{1}$, S. Rodríguez Sánchez ${ }^{1}$, E. González García ${ }^{2}$ L. Vicente Fatela ${ }^{1}$ y D. Samper Bernal ${ }^{3}$ \\ ${ }^{1}$ Unidad Multidisciplinaria para el Estudio y Tratamiento del Dolor Crónico. ${ }^{2}$ Sistemas de Información y Control de \\ Gestión. Hospital Universitario 12 de Octubre. ${ }^{3}$ Servicio de Anestesiología. Hospital Universitario Germans Trias $i$ \\ Pujol. Badalona (Barcelona)
}

Acedo Gutiérrez MS, Rodríguez Sánchez S, González García E, Vicente Fatela L, Samper Bernal D. Codificación clínica con la CIE9MC. Rev Soc Esp Dolor 2013; 20(2): 69-88.

\section{ACTUALIZACIÓN EN LA CODIFICACIÓN CLÍNICA DEL DOLOR. INTRODUCCIÓN}

La IASP' define el dolor como "una experiencia sensorial y emocional desagradable asociada con un daño tisular real o potencial, o descrita en términos de dicho daño". Esta es la definición hoy por hoy más aceptada. El dolor es siempre subjetivo. Cada individuo aprende el significado de la palabra a través de experiencias relacionadas con un daño en las etapas iniciales de la vida. Desde un punto de vista biológico, el estímulo que produce el dolor indica que su causa podría dañar los tejidos, es por tanto una información del sistema nervioso sobre todo lo que suponga una amenaza para la vida. Pero no es solo una sensación subjetiva, sino que al ser esa sensación siempre desagradable se convierte en una experiencia emocional, en sufrimiento. Esta definición incluye el dolor no originado por un daño tisular o sin causa patológica, esto es, el dolor psicógeno, ya que al ser una sensación subjetiva, no se puede diferenciar de la provocada por daño tisular.

Existen varios sistemas de clasificación, entre ellos el basado en los criterios de la IASP o en los de la OMS

Recibido: 30-05-12.

Aceptado: 21-01-13.
(CIE.9). Estas clasificaciones permiten disponer de un lenguaje normalizado, permitiendo que los clínicos e investigadores puedan realizar análisis comparativos con los mismos criterios, pero no reflejan aspectos psicopatológicos, es decir, criterios que engloben trastornos cognitivo-conductuales, medio-ambientales, sociales, etc., que acompañan muchas veces al dolor, ni la terminología que se utiliza actualmente en la clínica.

Cuando se comienza a codificar el dolor como enfermedad, las primeras dificultades que se encuentran con la CIE9MC es que no existía ninguna categoría específica que englobara todos los aspectos del mismo (aspectos biológicos, fisiológicos, conductuales, medioambientales y sociales). La CIE9MC permitía localizar la estructura anatómica afectada por el dolor, pero no aportaba información sobre las características del mismo, es decir, no se podía referenciar si se trataba de un dolor agudo o crónico, o de si estaba relacionado con una neoplasia o con un proceso postquirúrgico. Para clasificar estos y otros aspectos relacionados con el dolor, la ICD9CM incorporó en el año 2006 (6. ${ }^{a}$ edición CIE9MC 2008 en España) la categoría

\footnotetext{
${ }^{1}$ La IASP (International Association for the Study of Pain) se crea en el año 1975 como Asociación Mundial de los Especialistas en Dolor y su órgano de expresión es la revista Pain, cuyo capítulo en español fue creado en el año 1990. El desarrollo y adopción de nuevas definiciones, la revisión de términos universalmente aceptados y la clasificación de los síndromes dolorosos están entre los objetivos más importantes de la IASP. Por ello se creó el Subcomité de Taxonomía presidido por H. Menskey y un sistema de codificación centrado, sobre todo, en las manifestaciones físicas del dolor.
} 
338, "Dolor no clasificado bajo otros conceptos", incluida en el Capítulo 6 de Enfermedades del Sistema Nervioso y Órganos de los Sentidos (320-389).

Con este monográfico se quiere facilitar a los profesionales la codificación del dolor, tanto en su vertiente diagnóstica como terapéutica y unificar criterios, para intentar utilizar un mismo lenguaje y poder realizar análisis que reflejen la realidad de nuestra práctica clínica.

\section{CODIFICACIÓN DE DIAGNÓSTICOS}

\section{Normas generales de codificación}

\section{Información general sobre la codificación del dolor}

- Los códigos de la categoría 338, a menos que se indique expresamente lo contrario, se deben utilizar en combinación con códigos de otras categorías y capítulos para documentar mejor la información sobre el dolor agudo y crónico y el dolor neoplásico.

- Si el dolor no se especifica como agudo o crónico, no deben asignarse códigos de la categoría 338, excepto para el dolor postoracotomía, el dolor postoperatorio, el dolor neoplásico o el síndrome de dolor central.

- No se debe asignar un código de las subcategorías 338.1 Dolor agudo o 338.2 Dolor crónico cuando se conoce el diagnóstico de la patología subyacente que lo produce y de la cual el dolor forma parte de sus síntomas habituales, a menos que la consulta o el ingreso se realicen para el tratamiento o control del dolor o que durante dicho contacto sanitario el dolor haya precisado una evaluación o un tratamiento específico.

\section{Secuencia de los códigos de la categoría 338}

- Los códigos de la categoría 338 se utilizarán como diagnóstico principal, cuando el control o tratamiento del dolor sea la razón del ingreso o consulta. La patología subyacente del dolor, en estos casos, deberá ser registrada como un diagnóstico secundario.

- Paciente con intenso dolor agudo de espalda debido a hernia de disco intervertebral lumbar. Acude a la consulta del dolor para bloqueo epidural con esteroides y anestésicos locales:

- 338.19. Otro dolor agudo.

- 722.10. Desplazamiento de disco intervertebral lumbar sin mielopatía.

- 03.91. Inyección de anestésico en el conducto espinal para analgesia.

- 03.92. Inyección de otro agente en canal espinal.

- 99.23. Inyección de esteroide.
- Cuando el motivo del ingreso o consulta es la realización de un procedimiento cuyo objetivo sea el tratamiento de la patología subyacente que produce el dolor (p. ej: fusión espinal por fractura vertebral), se debe asignar el código de dicha patología como el diagnóstico principal, no debiendo asignarse códigos de la categoría 338, salvo que durante el ingreso necesite tratamiento específico distinto a la analgesia habitual para el control del dolor.

- Cuando el motivo del ingreso o consulta es el tratamiento de la patología subyacente y durante el ingreso es preciso realizar un tratamiento o procedimiento (p. ej. neuroestimulador) para el control del dolor, se asignará como diagnóstico principal el código de la patología subyacente y como diagnóstico secundario el código de dolor correspondiente.

- Paciente que ingresa para tratamiento quirúrgico de hernia discal lumbar, durante el ingreso presenta cuadro de dolor agudo que precisa la inserción de un neuroestimulador para control del mismo, descartándose la intervención quirúrgica.

- 722.10. Desplazamiento de disco intervertebral lumbar sin mielopatía.

- 338.19. Otro dolor agudo.

- V64.3. Procedimiento quirúrgico o de otro tipo no realizado por otros motivos.

- 86.96. Inserción o sustitución de neuroestimulador generador de pulsos.

- 03.93. Colocación o sustitución de cable(s) de neuroestimulador medular.

- Cuando un paciente ingresa o consulta para la realización de un procedimiento para el tratamiento del dolor se asignará como diagnóstico principal el código de dolor correspondiente.

- Paciente que ingresa para inserción de un neuroestimulador de un solo electrodo para control de dolor lumbar crónico por desplazamiento de disco intervertebral sin mielopatía.

- 338.29. Otro dolor crónico.

- 722.10. Desplazamiento de disco intervertebral lumbar sin mielopatía.

- 86.94. Inserción o sustitución de neuroestimulador generador de pulsos de un solo electrodo, no especificado como recargable.

- 03.93. Colocación o sustitución de cable(s) de neuroestimulador medular.

\section{Uso de los códigos de la categoría 338 en combinación con códigos de localización específica del dolor}

Los códigos de la categoría 338 se deben usar junto con códigos que identifiquen la localización del dolor (incluyendo códigos del capítulo 16) para completar la infor- 
mación, por ejemplo, si un código describe el lugar del dolor, pero no describe completamente si el dolor es agudo o crónico. La secuencia de los códigos de la categoría 338 con los códigos de localización específica del dolor (incluyendo los códigos del capítulo 16), dependerá del motivo del ingreso o consulta de la manera siguiente:

- Si el motivo de consulta o ingreso es el control del dolor, se asignará el código correspondiente de la categoría 338 seguido por el código que identifique el lugar específico del dolor.

- Si el ingreso o la consulta están motivados por cualquier otra razón diferente al tratamiento o control del dolor y no se ha establecido un diagnóstico definitivo relacionado, se asigna el código de localización específica del dolor en primer lugar, seguido por el código correspondiente de la categoría 338.

- Paciente que presenta dolor abdominal generalizado crónico de origen no establecido. Ingresa para diagnóstico y evaluación de la enfermedad, no llegándose a un diagnóstico definitivo y quedando pendiente de pruebas diagnósticas.

- 789.07. Dolor abdominal generalizado.

- 338.29. Otro dolor crónico.

\section{Dolor agudo}

El dolor agudo es el desencadenado por la lesión de los tejidos y por la activación de los nociceptores en el sitio del daño local. El dolor agudo dura un lapso de tiempo relativamente limitado y por lo común desaparece cuando se resuelve la alteración que lo provocó. Se observa después de traumatismos, intervenciones quirúrgicas y algunos cuadros patológicos (p. ej. inflamaciones).

Dentro de la categoría 338, el código correspondiente al dolor agudo es el 338.1. Siempre debe utilizarse un quinto dígito que identifique el origen del dolor:

- 338.11. Dolor agudo debido a trauma.

- 338.12. Dolor agudo postoracotomía.

- 338.18. Otro dolor agudo postoperatorio.

- 338.19. Otro dolor agudo (excluye el relacionado con neoplasia 338.3).

\section{Dolor crónico}

El dolor crónico suele definirse como aquel que se mantiene durante más de tres meses (para algunos autores más de seis) o perdura más allá de su curso habitual. El dolor crónico es aquel que persiste y es desproporcionado al proceso que lo origina, no evolucionando a la curación. En el paciente con dolor crónico el síntoma es la enfermedad, con el tiempo el dolor no solo no desaparece sino que se desarrolla un cuadro de sensibilización, no existiendo a menudo una correspondencia entre el sufrimiento experimentado y la magnitud de la lesión. No hay un tiempo claramente definido para que el dolor se convierta en crónico, debiendo estar documentada dicha condición en el informe clínico. El dolor crónico se clasifica en la subcategoría 338.2.

$\mathrm{Al}$ igual que en el dolor agudo, es necesario utilizar siempre un quinto dígito:

- 338.21. Dolor crónico debido a trauma.

- 338.22. Dolor crónico postoracotomía.

- 338.28. Dolor crónico postoperatorio.

- 338.29. Otro dolor crónico (excluye el relacionado con neoplasia 338.3).

\section{Dolor postraumático o debido a traumatismo}

Es el dolor que resulta de traumatismos graves, como por ejemplo traumatismo, torácico, abdominal o pélvico, quemaduras, fracturas óseas. El dolor se encuentra habitualmente de manera constante desde el momento de la lesión hasta la corrección de la misma (a menudo por medios quirúrgicos) y desde el momento que comienza la rehabilitación hasta que se recupera el funcionamiento normal. Así pues existe una fase aguda o de recuperación y otra de rehabilitación o crónica.

El dolor postraumático se codifica 338.11 si es agudo y 338.21 si es crónico. Se considerará diagnóstico principal si el dolor es el motivo de la consulta o el ingreso. Debe añadirse un código adicional para especificar el tipo de traumatismo.

- Ingreso para control y tratamiento de dolor agudo secundario a aplastamiento vertebral lumbar tras traumatismo.

- 338.11. Dolor agudo debido a trauma.

- 805.4. Fractura de columna vertebral lumbar sin mención de lesión medular.

- E928.9. Accidentes no especificados.

- Ingreso para control de dolor crónico localizado en muñeca secundario a fractura de Colles hace 9 meses.

- 338.21. Dolor crónico debido a trauma.

- 719.44. Dolor articular en mano.

- 905.2. Efecto tardío de fractura de extremidad superior.

- E989. Efectos tardíos de lesión, sin determinarse si fue infligido de forma accidental o intencionada.

\section{Dolor postoperatorio}

Es el dolor que se produce después de una cirugía. El dolor quirúrgico origina una respuesta endocrina que se traduce en una mayor secreción de corticoides, catecolaminas y otras hormonas propias de una respuesta de estrés, que puede influir en la morbilidad y la mortalidad perioperatoria. 
El dolor postoracotomía y otros dolores postoperatorios se clasifican en las subcategorías 338.1 y 338.2, dependiendo de si el dolor es agudo o crónico. Por defecto, los dolores postoperatorios no especificados como agudos o crónicos, se codifican como agudos.

- Dolor postoperatorio no asociado con complicación postoperatoria específica. Al dolor postoperatorio no asociado con una complicación postoperatoria específica se le asigna el código de dolor postoperatorio correspondiente de la categoría 338.

- Dolor postoperatorio asociado con complicación postoperatoria específica. El dolor postoperatorio asociado con una complicación postoperatoria específica se codificará con el código correspondiente a la complicación que se haya producido, añadiéndose el código apropiado de la categoría 338 para identificar el dolor agudo o crónico.

- Paciente que presenta dolor inguinal crónico por suturas metálicas de la malla permanentes tras reparación de hernia inguinal izquierda.

- 998.89. Otras complicaciones especificadas.

- 338.28. Otro dolor crónico postoperatorio.

- 789.04. Dolor abdominal, cuadrante inferior izquierdo.

- E878.8. Otras intervenciones y técnicas quirúrgicas especificadas.

- Dolor postoperatorio como diagnóstico principal. El dolor postoperatorio será registrado como diagnóstico principal cuando el motivo del ingreso o consulta sea el tratamiento o control de dicho dolor.

- El dolor postoperatorio habitual o esperado inmediatamente después de una cirugía no debe codificarse. Sin embargo, cuando el paciente desarrolla dicho dolor postoperatorio con inusual o desproporcionada intensidad y así es documentado por el médico responsable, sí debe ser codificado.

\section{Dolor debido a dispositivos, implantes e injertos}

El dolor asociado con dispositivos, implantes o injertos colocados en un lugar quirúrgico (p. ej. prótesis de cadera dolorosa) precisa de dos códigos, uno el código del capítulo 17 para describir la complicación y se utilizará además un código de la categoría 338 para identificar el tipo de dolor. Debe añadirse además un código $\mathrm{V}$ para identificar la localización anatómica en la que se encuentra el dispositivo, prótesis, etc.

- Dolor agudo en rodilla secundario a subluxación de prótesis de rodilla.

- 996.42. Luxación de prótesis articular.

- 338.18. Dolor agudo postoperatorio.

- 719.46. Dolor articular en pierna.

- V43.65. Estado de sustitución de articulación de rodilla.
- E878.1. Intervención quirúrgica con implante de dispositivo como causa de reacción anormal del paciente o de complicación posterior, sin mención de accidente en el momento de la intervención.

- Dolor crónico en cadera secundario a prótesis de cadera dolorosa, se decide intervención quirúrgica para recambio de prótesis.

- 996.77. Otra complicación por prótesis interna de articulación.

- 338.28. Otro dolor crónico postoperatorio.

- 719.45. Dolor articular en cadera.

- E878.1. Intervención quirúrgica con implante de dispositivo como causa de reacción anormal del paciente o de complicación posterior, sin mención de accidente en el momento de la intervención.

- V43.64. Estado de sustitución de articulación de cadera.

\section{Dolor oncológico o relacionado con neoplasia}

El dolor oncológico es el producido por una neoplasia, cáncer o tumor. Incluye el dolor que depende de la evolución de la enfermedad y el debido a los tratamientos.

El dolor documentado como relacionado, asociado o debido a una neoplasia maligna tanto primaria como secundaria (metástasis) tiene código propio y se asigna tanto para el dolor agudo como crónico, 338.3, Dolor (agudo) (crónico) relacionado con una neoplasia.

Este código se asignará como diagnóstico principal cuando el motivo del ingreso o consulta esté documentado como manejo o control del dolor y la neoplasia debe ser registrada como un diagnóstico adicional.

Cuando la razón del ingreso o consulta sea para tratamiento, diagnóstico o seguimiento de una neoplasia y el dolor asociado con la misma también esté documentado, el código 338.3 se asignará como diagnóstico secundario. El código del dolor por sitio no se debe asignar, ya que la topografía de la neoplasia proporciona información de la localización del dolor.

- Ingreso para control de dolor crónico oncológico localizado a nivel abdominal secundario a carcinoma de páncreas.

- 338.3. Dolor (agudo) (crónico) relacionado con una neoplasia.

- 157.9. Neoplasia maligna de páncreas de localización no especificada.

- M8010/3 Carcinoma NEOM.

- Ingreso para estudio por dolor agudo en fémur derecho en paciente en tratamiento de adenocarcinoma prostático, siendo diagnosticado de metástasis ósea en fémur. Durante el ingreso precisa la valoración y tratamiento por la unidad del dolor. 
- 198.5. Neoplasia maligna secundaria de huesos y médula ósea.

- M8140/6 Adenocarcinoma metastásico.

- 338.3. Dolor (agudo) (crónico) relacionado con una neoplasia.

- 185. Neoplasia maligna de próstata.

- M8140/3. Adenocarcinoma NEOM.

\section{Dolor neuropático}

El dolor neuropático es el causado por una lesión o disfunción del sistema de transmisión del dolor, es decir del sistema nervioso, bien a nivel del sistema nervioso central, periférico o del sistema simpático. La codificación del dolor neuropático sigue los criterios definidos en las normas generales (punto 1.1) que son aplicables a todas las entidades que se describen a continuación.

\section{Dolor neuropático de origen central}

Es el dolor iniciado o causado por una lesión primaria o disfunción del sistema nervioso central. La lesión se puede localizar a nivel de la médula espinal, denominándose dolor central por lesión medular o dolor mielopático, cuya causa puede ser por ejemplo una sección medular (apareciendo dolor por debajo de la lesión), una mielitis transversa en una esclerosis múltiple o una siringomielia. También la lesión puede localizarse a nivel cerebral, por encima de la unión bulbomedular, tanto a nivel de la corteza como del tálamo (dolor talámico), cuya etiología suele ser vascular (ictus).

Existe un código específico para el dolor de origen central, el 338.0, Síndrome de dolor central. Se debe añadir un segundo código que indique la patología subyacente.

- Dolor crónico neuropático central debido a siringomielia.

- 338.0. Síndrome de dolor central.

- 336.0. Siringomielia y siringobulbia.

- Ingreso para tratamiento de dolor crónico neuropático central secundario a ictus o ACVA.

- 438.89. Otros efectos tardíos de enfermedad cerebrovascular.

- 338.0. Síndrome de dolor central.

\section{Dolor neuropático de origen periférico}

Es el dolor iniciado o causado por una lesión primaria o disfunción del sistema nervioso periférico, es decir, raíces nerviosas, plexos nerviosos y nervios.

- La radiculopatía o radiculitis es el dolor provocado por la distensión de las raíces cervicales o lumbares debido, por ejemplo, a la compresión de un disco o una prominencia.

- IAE

- Dolor(es) (de), doloroso (a):

- Radicular.

- Raíz.

- Radiculopatía.

Los códigos varían según la localización:

- Braquial o cervical (síndrome radicular de miembros superiores) 723.4.

- Torácica. 724.4.

- Lumbar/lumbosacra (síndrome radicular de miembros inferiores) 724.4.

- No especificada. 729.2.

Se excluyen las producidas por espondilosis (721.0721.9), trastornos del disco intervertebral (722.0-722.9) o por vértebras colapsadas (codificar según causa).

- La plexopatía hace referencia a la lesión de un plexo nervioso. A nivel de las extremidades, las ramas anteriores de los nervios espinales forman unas complejas redes nerviosas, llamadas plexos nerviosos, distinguiéndose el plexo cervical, braquial y lumbosacro. Aparece dolor en el territorio de inervación del plexo correspondiente, asociándose alteraciones sensitivas y motoras. La etiología puede ser postraumática, por compresión, post-radioterapia, entre otras.

- IAE.

- Plexitis braquial 353.0.

- Plexo braquial, síndrome de 353.0.

- Lesión, plexo lumbosacro 353.1

- La neuritis o neuralgia se define como el dolor en el territorio de distribución de uno o varios nervios. En general, si se afecta un solo nervio se habla de mononeuritis y si se afectan varios de polineuropatía o polineuritis.

- Las mononeuritis, dolor en el territorio de un solo nervio, se encuentran codificadas en las categorías 354 Mononeuritis de miembro superior y mononeuritis múltiple y 355 Mononeuritis de miembro inferior y sitio no especificado. Excluyen la neuralgia o neuritis del nervio ciático o comúnmente conocida como ciática (724.3). Algunos ejemplos, frecuentes en la práctica clínica, son:

- Neuritis del nervio mediano, de la palma de la mano o palmar 354.1.

- Neuralgia ilioinguinal 355.8 .

- Meralgia parestésica 355.1.

- Neuralgia, neuroma o metatarsalgia de Morton (lesión del nervio plantar) 355.6.

- Neuralgia intercostal 353.8.

- Neuralgia occipital 723.8.

- Neuralgia postherpética 053.19. Excluye neuralgia del trigémino postherpética 053.12.

- Las polineuropatías se clasifican en la categoría 357 Neuropatía inflamatoria y tóxica. Cuando la poli- 
neuropatía se debe a una enfermedad o condición subyacente, esta debe ser secuenciada antes que la polineuropatía.

- Consulta para tratamiento de dolor crónico neuropático secundario a una polineuropatía diabética por DM2.

- 338.29. Otro dolor crónico.

- 250.60. Diabetes tipo 2 o no específica con manifestaciones neurológicas.

- 357.2. Polineuropatía en diabetes.

- Dolor crónico neuropático secundario a una polineuropatía por alcoholismo crónico.

- 338.29. Otro dolor crónico.

- 357.5. Polineuropatía alcohólica.

- 303.90. Alcoholismo crónico.

- Ingresa para tratamiento de dolor agudo neuropático en paciente con polineuropatía producida por tratamiento con quimioterapia.

- 338.19. Otro dolor agudo.

- 357.6. Polineuropatía por fármacos.

- E933.1. Fármacos antineoplásicos o inmunosupresores.

- Las neuralgias de los pares craneales se encuentran codificadas en las categorías 350-352. Algunos ejemplos que aparecen frecuentemente en la práctica clínica son:

- Neuralgia del trigémino 350.1 (053.12, si es de origen postherpético).

- Algia facial atípica 350.2.

- Neuralgia glosofaríngea 352.1.

- El dolor de nervio o el dolor de raíz o radicular no especificado se codifica con el código 729.2. Neuralgia, neuritis y radiculitis no especificada.

\section{Otros dolores neuropáticos}

Existen algunos síndromes de dolor neuropático con entidad propia que se describen a continuación:

- Síndrome de dolor regional complejo tipo I. Este síndrome es un trastorno doloroso que agrupa a una serie de entidades tales como la atrofia de Sudeck, la distrofia neurovascular refleja, la algodistrofia o la distrofia simpático-refleja. Suele surgir después de un hecho nocivo desencadenante (inmovilización prolongada, fractura, intervención), apareciendo dolor en un territorio que no se limita a la distribución de un solo nervio periférico y sin proporción con el hecho desencadenante. Se acompaña de edema y cambios vasomotores, entre otros. Aunque en la definición actual se trata de un mismo cuadro clínico, el índice alfabético proporciona códigos distintos dependiendo de que su origen sea o no postraumático:

- IAE.
- Distrofia.

- Simpática postraumática 337.20.

- Especificada NCOC 337.29.

- Miembro inferior 337.22.

- Miembro superior 337.21.

- Algoneurodistrofia 733.7.

- Síndrome.

- Sudeck, de 733.7.

- Síndrome de dolor regional complejo tipo II, antes conocido como causalgia. Se caracteriza por la presencia de dolor de características quemantes y urentes, ante estímulos no dolorosos como el roce (alodinia), después de una lesión traumática sobre un nervio, asociada a menudo con disfunción vasomotora y cambios tróficos posteriores.

- IAE.

- Causalgia 355.9.

- Miembro inferior 355.71.

- Miembro superior 354.4.

Si está suficientemente documentado el origen, postraumático o postquirúrgico, y el curso, agudo o crónico, se asignan los códigos de dolor correspondiente.

- Síndrome del miembro fantasma doloroso o dolor fantasma. El síndrome del miembro fantasma doloroso hace alusión al dolor percibido en una parte del cuerpo que falta y aparece aproximadamente en el 50-80\% de todos los amputados, siendo más intenso en las porciones más distales del miembro fantasma.

- IAE.

- Síndrome.

- Miembro fantasma, 353.6.

\section{Síndrome de dolor crónico}

Es el dolor crónico asociado con una disfunción psicosocial importante. Se caracteriza por:

- Persistente (+ de 6 meses) o recurrente.

- Poca respuesta al tratamiento.

- Provocar un deterioro significativo y progresivo de las capacidades funcionales y relacionales del paciente en sus actividades de la vida diaria, tanto en su domicilio o en el trabajo.

No se debe confundir la expresión "dolor crónico", con el Síndrome de dolor crónico, 338.4. Esta entidad solo debe usarse cuando en el informe clínico se documente específicamente esta condición.

\section{Dolor psicógeno}

Se considera que existe dolor psicógeno cuando no es posible identificar un mecanismo nociceptivo o neuropático y hay suficientes síntomas psicológicos para cumplir 
con los criterios de afección con dolor somatiforme, depresión y otros de la categoría diagnóstica DSM-IV que se relaciona con las quejas de dolor. No hay que olvidar que el dolor psicógeno es real y que precisa tratamiento específico. Una situación diferente es la presencia de dolor asociado con factores psicológicos, no atribuido exclusivamente a ellos.

- IAE.

- Dolor.

- Psicógeno 307.80.

\section{Otros tipos de dolor}

Se describen a continuación algunos cuadros que aparecen en la práctica clínica y que no se han incluido en apartados anteriores.

\section{Dolor en cicatriz}

La cicatriz dolorosa, se codifica con el código 709.2. Estados cicatriciales y fibrosis de la piel

- IAE.

- Dolor.

- Cicatriz NCOC.

- Cicatriz, cicatrización (adherente) (contraída) (dolorosa)(viciosa) 709.2.

Si la cicatriz es queloide el código a utilizar es el 701.4.

\section{Síndrome de dolor miofascial}

Se caracteriza por la presencia de puntos hipersensibles, llamados "gatillo", en el interior de uno o más músculos o en el tejido conectivo circundante, que se asocian a dolor a la palpación y espasmo, rigidez y limitación del movimiento. El dolor por lo general se irradia a una zona distante desde el punto gatillo. El código correspondiente es 729.1 Mialgia, miositis, fibromiositis no especificada.

- IAE.

- Dolor.

- Músculo 729.1.

\section{Fibromialgia}

La fibromialgia es un síndrome clínico que se caracteriza por dolor difuso (por encima y por debajo de la cintura, y de forma bilateral) de tipo crónico y puntos múltiples de sensibilidad. Asocia otros síntomas como fatiga, alteración del sueño, ánimo depresivo, ansiedad.

- IAE.

- Fibromialgia 729.1.

\section{Síndrome de la boca quemante o glosodinia}

Es el dolor urente de la mucosa intrabucal que no se asocia a ninguna enfermedad que lo provoque.

- IAE.

- Síndrome de la boca quemante, glosodinia o glosopirosis 529.6.

\section{Dolor de origen musculoesquelético en la columna vertebral}

El dolor musculoesquelético es el motivo de consulta por dolor más frecuente, y concretamente el dolor localizado en la columna vertebral. Asimismo es el que requiere la utilización de más recursos (procedimientos) diagnósticos y terapéuticos. La codificación del dolor musculoesquelético, se debe realizar teniendo en cuenta la normativa general explicada anteriormente en todas las entidades que se describen en este apartado.

El dolor musculoesquelético es el que se produce como consecuencia de enfermedades o disfunciones de alguno de los componentes del aparato locomotor (huesos, articulaciones, ligamentos, músculos o tendones). Provocan este tipo de dolor las enfermedades degenerativas osteoarticulares que son las más frecuentes del género humano y cuyo síntoma cardinal es el dolor. También son causa de este tipo de dolor, un número importante de enfermedades inflamatorias y disfunciones. En la mayoría de los casos la evolución de la enfermedad provocará impotencia funcional, ocasionando un gran impacto sobre la salud y la calidad de vida de la población.

\section{Descripción de la columna vertebral}

La columna vertebral constituye el eje de nuestro cuerpo, sobre el que se articulan las extremidades mediante la cintura pélvica (pelvis) y la escapular (hombro). Se distinguen las siguientes regiones: cervical (7 vértebras), torácica o dorsal (12 vértebras), lumbar (5 vértebras), sacro (5 vértebras fusionadas) y cóccix (3-5 vértebras). La columna presenta una forma sinuosa con curvaturas laterales que aumentan la resistencia y favorecen la estática. En las regiones cervical y lumbar, la curvatura es anterior y se denomina lordosis; mientras que en las regiones torácica y sacra, la curva es posterior y se llama cifosis.

La vértebra tipo es un hueso corto formado por varias partes. El primer detalle a destacar es el cuerpo de la vértebra que forma el pilar anterior de la columna. El cuerpo tiene dos caras intervertebrales para articularse mediante un disco intervertebral con las dos vértebras contiguas. En la parte posterior, se encuentra un arco vertebral con tres 
apófisis: dos laterales, las apófisis transversas, y una dorsal, la apófisis espinosa. La parte del arco que está entre las apófisis transversas y la espinosa se denomina lámina vertebral. El arco vertebral se une con el cuerpo mediante los pedículos. De ellos salen dos apófisis articulares superiores (para articularse con la vértebra superior) y dos apófisis articulares inferiores (con la vértebra inferior), denominadas zigoapofisarias. Todo este conjunto forma el pilar posterior de la columna.

Entre el arco vertebral y la cara posterior del cuerpo de la vértebra se forma un agujero por donde pasa la médula espinal, llamado foramen vertebral. Tiene forma triangular y constituye a lo largo de toda la columna el canal vertebral. Los pedículos tienen una escotadura vertebral superior y otra inferior, que al articularse forman el foramen intervertebral o agujero de conjunción, por donde salen los nervios espinales.

En la columna vertebral existen una serie de patologías específicas que cursan con dolor, que se describen a continuación.

\section{Espondiloartrosis y espondilosis}

La artrosis es la enfermedad reumática más común y se caracteriza por la alteración del cartílago articular. La espondiloartrosis es la artrosis que se localiza en la columna vertebral y se trata de un proceso degenerativo que afecta a las articulaciones discovertebrales e interapofisarias de las vértebras, y que puede aparecer de forma aislada o, lo que es más frecuente, formando parte de un proceso degenerativo articular generalizado. Se denomina síndrome facetario al proceso degenerativo de las articulaciones interapofisarias posteriores. Se denomina espondilosis cuando afecta a las articulaciones discovertebrales y simplemente artrosis cuando afecta a las interapofisarias. Los discos que soportan más peso (L4, L5, S1) son los que se afectan con mayor frecuencia. La presencia de osteofitos vertebrales que se introducen hacia el interior del conducto vertebral puede dar lugar a cuadros de dolor radicular por compresión e irritación de las raíces nerviosas. En casos extremos puede estenosarse el canal raquídeo produciéndose mielopatía.

La entrada en el índice alfabético se realiza a través de espondilosis y los términos espondiloartrosis y espondilartrosis nos llevan a él por referencia cruzada. El código varía según la localización en la columna y según la presencia

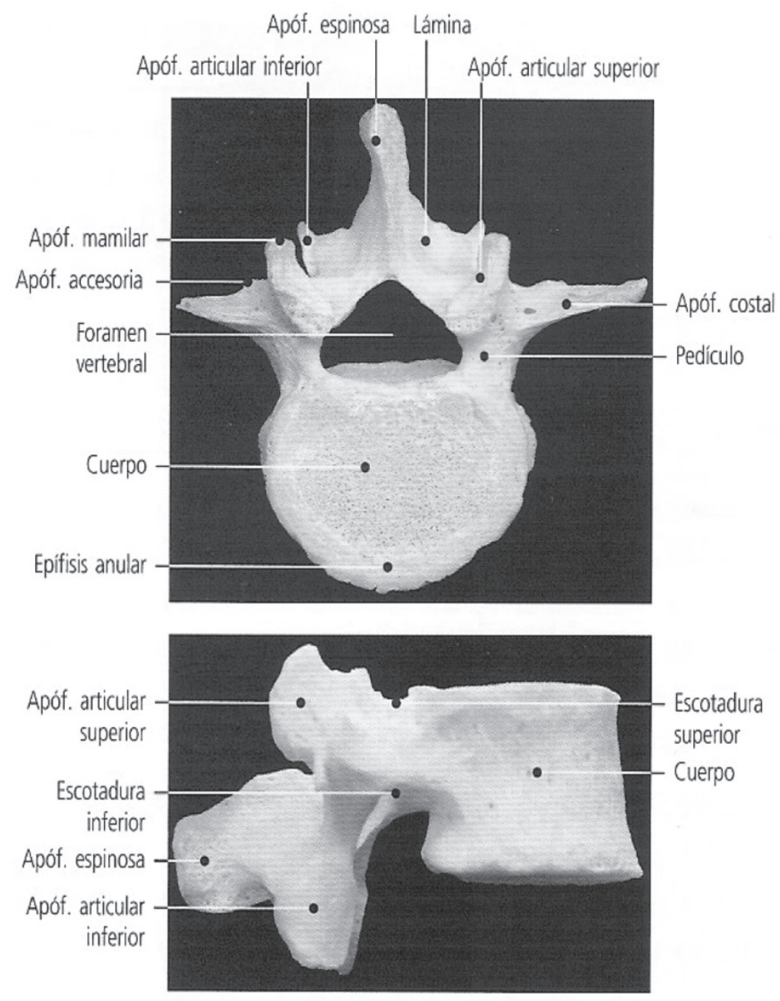

Fig. 2.
Fig. 1.

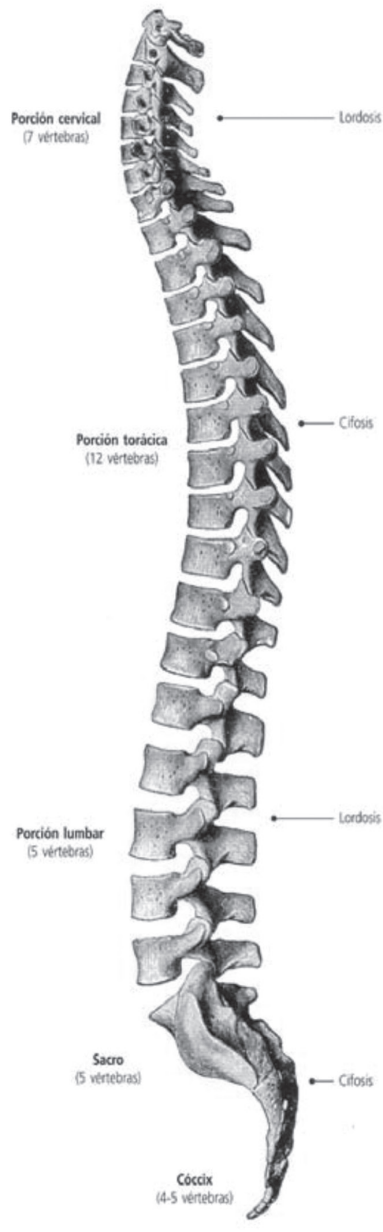


o no de mielopatía. Ni la localización de la artrosis "intravértebra" ni la presencia de radiculopatía varían el código.

- IAE.

- Espondilartrosis (véase además Espondilosis) 721.90.

- Espondilosis 721.90.

- Con mielopatia NCOC 721.91.

- Cervical, cervicodorsal 721.0.

- Con mielopatía 721.1.

- Inflamatoria 720.9.

- Lumbar, lumbosacra 721.3.

- Con mielopatía 721.42.

\section{Espondilolisis y espondilolistesis}

Las vértebras se unen a través de las apófisis articulares superior e inferior, denominándose esta unión "pars interarticularis". El término espondilolisis describe un defecto de la parte interarticular. La espondilolistesis es una alteración causada por la espondilolisis, en la que una vértebra se desliza hacia delante en relación con la inferior. La localización más frecuente es L5 sobre S1 o L4 sobre L5. Existen diversos grados, según el desplazamiento, y en ocasiones se produce atrapamiento de las raíces nerviosas lumbares, lo que origina dolor neuropático de tipo radicular. Puede ser congénita o adquirida, secundaria a fracturas por fatiga, traumatismo o degeneración discal. El dolor forma parte habitual de la sintomatología de estas dos entidades. Tanto la espondilolisis como la espondilolistesis asocian dolor y tienen entrada directa por el índice alfabético.

- IAE.

- Espondilolisis (congénita) 756.11.

- Adquirida 738.4.

- Cervical 756.19.

- Región lumbosacra 756.11.

- Que afecta al feto o al recién nacido 763.1.

- Espondilolistesis (congénita) (lumbosacra) 756.12.

- Adquirida 738.4.

- Degenerativa 738.4 .

- Traumática 738.4 .

\section{Hernia discal}

Los cuerpos vertebrales de la columna se articulan entre sí mediante los llamados discos intervertebrales, compuestos por dos porciones: una gelatinosa central, el núcleo pulposo, y otra circunferencial, el anillo fibroso. El prolapso o desplazamiento del disco intervertebral es lo que se denomina hernia de disco. Las manifestaciones clínicas de la herniación de un disco son: a) dolor (neuropático) en las extremidades, inferiores o superiores dependiendo de la localización, y b) entumecimiento o debilidad en las mismas, con una distribución por dermatomos, denomi- nándose radiculopatía. Asimismo, aunque menos frecuente, puede dañarse la médula espinal, apareciendo síntomas de mielopatía, que varían según la localización de la lesión. En el concepto diagnóstico de hernia discal se incluyen manifestaciones clínicas como el dolor, neuritis, radiculitis o ciática, por lo que cualquiera de estos síntomas quedaría recogido al codificar la hernia. La entrada por el I.A. debe realizarse buscando el término desplazamiento.

- IAE.

- Hernia, herniario (adquirida) (recurrente) 553.9.

- Disco, intervertebral véase Desplazamiento, disco intervertebral.

- Desplazamiento, desplazado.

- Disco intervertebral (con neuritis, radiculitis, ciática u otro dolor) 722.2.

- Con mielopatía 722.70.

- Cervical, cervicodorsal, cervicotorácico 722.0.

- Con mielopatía 722.71.

\section{Síndrome de cirugía fallida de espalda}

Este síndrome, también denominado síndrome postlaminectomía, se refiere al dolor crónico, persistente o recurrente, posterior a uno o más procedimientos quirúrgicos de columna. Su prevalencia es superior al $25 \%$ y es proporcional al número de intervenciones quirúrgicas realizadas sobre la columna. La etiología más frecuente es la selección incorrecta de los pacientes, seguida por el dolor debido a daño irreversible del nervio antes de la intervención, una técnica quirúrgica mal realizada y la presencia de fibrosis postquirúrgica perirradicular, entre otras. Tiene entrada directa en el índice alfabético por síndrome postlaminectomía y el código varía según la localización anatómica:

- IAE.

- Síndrome.

- Postlaminectomía 722.80.

- Cervical, cervicotorácico 722.81.

- Lumbar, lumbosacra 722.83.

- Torácica, toracolumbar 722.82 .

\section{Estenosis del canal}

Es un síndrome que consiste en el estrechamiento del canal raquídeo, que crea un compromiso sobre los elementos neurales. La localización más frecuente es la lumbar. Puede ocurrir como consecuencia de diversas alteraciones que pueden ser: congénitas o adquiridas (artrosis de las articulaciones interapofisarias, osteofitos, protrusión discal, espondilolisis y espondilolistesis, iatrogénica por laminectomía, artrodesis).

La expresión clínica de la estenosis del canal raquídeo es la claudicación neurógena de la marcha. Esta se define 
como un dolor que se percibe en la región del glúteo, los muslos o piernas, al estar de pie o caminar y que se alivia descansando en posición de sentado. A veces, aunque poco frecuente, puede presentarse un síndrome de cola de caballo (alteraciones de los esfínteres, trastornos sexuales).

- IAE.

- Estenosis.

- Espinal 724.00.

- Cervical 723.0.

- Lumbar, lumbosacra 724.02.

- Nervio (raíz) NCOC 724.9.

- Región especificada NCOC 724.09.

- Torácica, toracolumbar 724.01.

El síndrome de cola de caballo tiene entrada en el índice alfabético como síndrome cauda equina, sin mención de vejiga neurógena 344.60 y con mención de vejiga neurógena 344.61.

\section{Coccigodinia}

Se caracteriza por dolor en "la punta terminal" de la columna vertebral o coxis, con irradiación a la parte inferior del sacro y el perineo. En el índice alfabético tiene entrada directa, siendo su código el 724.79.

\section{Anomalías congénitas raquídeas}

Las malformaciones congénitas de la columna vertebral son más frecuentes en las regiones dorsal inferior, lumbar y sacra. No existe evidencia de que las anomalías congénitas causen dolor por sí mismas.

- IAE.

- Anomalía (congénita).

- Espina dorsal, espinal 756.10.

\section{Desviaciones de la columna vertebral}

Las desviaciones de la columna vertebral se buscan en el índice alfabético por el término "Deformidad espina".

- IAE.

- Deformidad 738.9.

- Espina (adquirida) NCOC 738.5.

- Cifoscoliótica (véase además Cifoscoliosis) 737.30.

- Cifótica (véase además Cifosis) 737.10.

- Congénita 756.10.

\section{Esguince cervical}

Se define como el dolor cervical ocasionado por una acción que provoca una súbita aceleración y desaceleración de la cabeza y cuello respecto al tronco. Frecuentemente se produce en accidentes de tráfico con impacto posterior. El dolor vertebral puede ser causado por una o varias lesiones que afectan a la columna cervical.

Tiene entrada directa en el índice alfabético por "Esguince cervical, cervicodorsal, cervicotorácico" y también por "Latigazo, traumatismo o síndrome de", y el código correspondiente es el 847.0.

\section{Otras enfermedades que afectan a la columna vertebral}

La columna vertebral puede verse afectada por diversas patologías, que incluyen enfermedades óseas metabólicas, enfermedades sistémicas y procesos infecciosos, que pueden producir dolor. En muchas ocasiones será necesario utilizar más de un código, para describir la patología subyacente.

Enfermedades óseas metabólicas

- Osteoporosis. La OMS define la osteoporosis como «enfermedad caracterizada por una baja masa ósea y deterioro de la microarquitectura del tejido óseo, que conduce a un aumento de la fragilidad del hueso y en consecuencia el riesgo de fractura».

La osteoporosis tiene entrada directa por el índice alfabético y se codifica según el tipo, independientemente de la localización (lumbar, dorsal, cervical). Los principales tipos de osteoporosis y sus códigos correspondientes son:

- 733.00. Osteoporosis (generalizada) no especificada.

- 733.01. Osteoporosis postmenopáusica o senil.

- 733.02. Osteoporosis idiopática.

- 733.03. Osteoporosis por desuso.

- 733.09. Otra (osteoporosis inducida por drogas o fármacos, en estas es preciso utilizar código $\mathrm{E}$ adicional para identificar el fármaco).

Las fracturas vertebrales se definen como la pérdida de un $15 \%$ o más de la altura del cuerpo vertebral, y pueden producirse de forma espontánea o con mínimos esfuerzos. La codificación del dolor producido por una fractura vertebral secundaria a osteoporosis, se realizará teniendo en cuenta las circunstancias de consulta o ingreso:

- Si el ingreso se produce a consecuencia de la fractura, el diagnóstico principal será la osteoporosis seguido del código de fractura patológica y a continuación el código de dolor correspondiente. Como salvedad, si el ingreso se realiza para el tratamiento de la fractura y la enfermedad de base ya está previamente diagnosticada, se codificará en primer lugar la fractura patológica. 
- Si la consulta se realiza para el tratamiento del dolor, el dolor será el diagnóstico principal, añadiendo a continuación el código correspondiente a la osteoporosis y a la fractura patológica.

- Ingreso por fractura aplastamiento vertebral espontáneo, debido a osteoporosis idiopática. Intenso dolor agudo en las primeras horas que no cede con analgesia habitual por lo que se decide cursar interconsulta a Unidad de dolor.

- 733.02. Osteoporosis idiopática.

- 733.13. Fractura patológica de vertebras.

- 338.19. Otro dolor agudo.

- Hiperparatiroidismo. Es un trastorno del metabolismo del calcio, los fosfatos y el hueso por aumento de la secreción de la hormona paratiroidea. Se produce un recambio óseo elevado dando lugar a una disminución del hueso cortical y la resistencia ósea, aumentando el riesgo de fractura. Los pacientes pueden experimentar dolores óseos, pudiendo aparecer dolor asociado a fracturas de los cuerpos vertebrales. La artropatía secundaria que puede aparecer en este cuadro se clasifica con el código 713.0. Artropatía asociada con otros trastornos endocrinos y metabólicos. Este código precisa la descripción de la patología subyacente que deberá secuenciarse en primer lugar. Si además se asocia una fractura patológica de la vértebra también deberá añadirse el código, 733.13.

- Enfermedad ósea de Paget. Es un trastorno óseo que afecta a zonas del esqueleto debido a un mayor remodelamiento del hueso, resultando un hueso mal estructurado, más susceptible a deformidades y fracturas. El $60 \%$ de los pacientes presentan afectación de la columna lumbar y huesos de la pelvis. El dolor es el síntoma de presentación más común y aparece en la región del hueso o huesos afectados. La entrada en el índice alfabético se realiza buscando los términos de enfermedad hueso o bien osteitis deformante.

- IAE.

- Enfermedad (de), enfermo véase además Síndrome - Hueso 733.90.

- Paget (osteitis deformante) 731.0.

- Osteitis.

- Deformante (de Paget) 731.0.

Enfermedades sistémicas que afectan a la columna vertebral

Son una serie de enfermedades que pueden ocasionar dolor musculoesquelético y que pueden afectar no solo a la columna vertebral sino a otras regiones del organismo.

A continuación se describen algunas de estas enfermedades.

- Enfermedades reumatológicas. Muchas enfermedades reumáticas inflamatorias con afectación del raquis lumbar cursan con dolor lumbar como síntoma predominante. Entre ellas destacan la espondilitis anquilosante y la artritis reumatoide vertebral, ambas entidades se codifican con el código 720.0 espondilitis anquilosante.

- Enfermedades gastrointestinales. Algunas enfermedades inflamatorias intestinales como la colitis ulcerosa NEOM (556.9) o la enfermedad de Crohn NEOM (555.9) pueden cursar con artropatía asociada (713.1).

- Enfermedades neurológicas. Algunas enfermedades neurológicas pueden asociar artropatía (artropatía neuropática) que afecte a la columna vertebral. Por ejemplo la enfermedad de Charcot-Marie-Tooth (356.1) o la poliomielitis (045.0-045.9). Es preciso asociar el código de la artropatía asociada (713.5).

Procesos infecciosos que afectan a la columna vertebral

Las infecciones que afectan a la columna vertebral se pueden localizar a nivel de hueso (osteomielitis), musculatura paravertebral, articulaciones (artritis séptica) y discos intervertebrales (discitis). Pueden ser agudas o crónicas y dar lugar a secuelas que cursan con dolor.

El dolor crónico puede ser la secuela resultante de una infección aguda o crónica y debe codificarse siguiendo la normativa de efectos tardíos.

Consulta a Unidad de dolor para tratamiento de dolor crónico de cadera secundario a artropatía de cadera derecha, secuela de enfermedad de Lyme ya resuelta.

- 338.29. Otro dolor crónico.

- 719.45. Dolor articular región pélvica.

- 139.8. Efecto tardío de otras enfermedades infecciosas o parasitarias.

- 711.85. Artropatía asociada con otras enfermedades infecciosas y parasitarias, región pélvica.

\section{CODIFICACIÓN DE PROCEDIMIENTOS}

Para el tratamiento del dolor se utilizan una serie de procedimientos que no se encuentran referidos en ningún capítulo específico de la CIE9MC, sino que aparecen contemplados en diversos capítulos de la lista tabular de procedimientos. Debido a ello, en este monográfico se ha tomado como base el Catálogo de procedimientos de las Unidades de Dolor crónico realizado por el Panel de Expertos de la Sociedad Madrileña del Dolor y que coinciden con los incluidos en el documento editado por el Ministerio de Sanidad, Política Social e Igualdad, sobre "Estándares y recomendaciones en las Unidades de Dolor".

En este apartado del monográfico se describe: el procedimiento, la técnica para su realización y su codificación. 
La descripción se ha realizado agrupando los procedimientos en tres grandes grupos:

- Procedimientos no invasivos.

- Procedimientos mínimamente invasivos.

- Procedimientos invasivos y quirúrgicos.

\section{Procedimientos no invasivos}

\section{Iontoforesis}

Es una técnica empleada para introducir fármacos en el organismo a nivel local. Se realiza aplicando corriente continua o galvánica para que el medicamento ionizado pase a través de la piel.

Técnica. El sistema está formado por un generador de corriente que funciona con una pila, del que salen uno o dos pares de cables que terminan en dos electrodos (positivo y negativo) a los que se adhieren los parches almohadillados cargados con medicación. Estos se fijan a la piel del paciente en la zona de tratamiento.

- IAP.

- Iontoforesis, 99.27.

\section{Estimulación eléctrica transcutánea (TENS)}

Es una técnica no invasiva que consiste en estimular fibras nerviosas de la piel mediante la aplicación de una corriente eléctrica, con la intensidad adecuada para no estimular las terminaciones nerviosas que conducen la sensibilidad dolorosa y sí otras terminaciones nerviosas sensoriales, como las táctiles.

Técnica. El TENS consta básicamente de un generador portátil, que emite impulsos eléctricos con una intensidad, frecuencia y anchura de pulso prefijadas. A través de uno o dos pares de cables, está conectado a un electrodo positivo y otro negativo que se adhieren a la piel del paciente mediante un parche conductor colocado sobre la zona a tratar. Existe otro dispositivo compuesto por dos electrodos, que lleva integrada una batería con autonomía para 500 horas.

- IAP.

- Estimulación (electrónica)- véase además Implante. Estimulador electrónico

- Nervio.

- Periférico o médula espinal, transcutánea 93.39.

\section{Parche cutáneo de capsaicina al 8\%}

Consiste en la aplicación tópica, directamente sobre la zona de dolor, de parches de capsaicina al 8\% con el fin de bloquear el estímulo doloroso. La exposición de los nociceptores a altas dosis de capsaicina produce la desfuncio- nalización de los mismos y la reducción de la densidad de las fibras nerviosas epidérmicas.

Técnica. La manipulación y administración de este parche exige unas medidas de precaución y la supervisión médica. Se delimita la zona a tratar y se aplica sobre ella una capa de pomada anestésica. Cuando el anestésico ha hecho efecto (60 minutos), se aplica el parche de capsaicina al $8 \%$, y se deja actuar entre 30 y 60 minutos.

Las aplicaciones tópicas no tienen código CIE.

\section{Terapia psicológica}

La psicoterapia es la elaboración consciente de los conflictos psíquicos; busca mejorar la salud mental y, como consecuencia, la salud física.

Existen varias escuelas pero lo más importante es emplear la terapia adecuada a las necesidades del paciente. Las técnicas cognitivo-conductuales son las más empleadas en el tratamiento del dolor y se nutren de la investigación científica, dando un enfoque metodológico a la solución de los problemas psicológicos.

La psicoterapia se encuentra codificada en la subcategoría 94.3 Psicoterapia individual. En la práctica clínica las técnicas más utilizadas son:

- Hipnosis. 94.32.

- Terapia de comportamiento (cognitivo-conductual) individual. 94.33.

- Otra psicoterapia individual (biofeedback). 94.39.

\section{Procedimientos mínimamente invasivos}

\section{Estimulación eléctrica percutánea}

Esta técnica consiste en la administración de corriente eléctrica directamente en los tejidos profundos con el fin de estimular las fibras sensitivas próximas a la zona patológica origen del dolor.

Técnica. El sistema está formado por un generador que emite impulsos con una intensidad y un periodo de tiempo establecidos. Del generador sale un cable de conexión, que varía de forma según la región a tratar y sirve de guía para colocar los 10 electrodos de los que consta el sistema. El electrodo termina en un filamento de acero inoxidable que se introduce en la dermis para alcanzar la zona de tratamiento.

Codificación. Se utiliza el mismo código que para la estimulación transcutánea, 93.39.

\section{Terapia parenteral}

Consiste en la administración subcutánea, intramuscular o intravenosa de diversos fármacos. En el tratamiento del 
dolor se utilizan analgésicos, incluidos opioides, corticoides, bifosfonatos y anestésicos locales, entre otros.

Técnica. Con una aguja o catéter del calibre y longitud adecuados se accede a la zona de inyección y se procede a la infusión del medicamento previamente cargado en jeringa o bolsa dosificadora.

Codificación. La administración de fármacos antiálgicos por vía parenteral se codifica en la subcategoría 99.2, Inyección o infusión de otra sustancia terapéutica o profiláctica. Incluye: inyección o infusión, de acción local o sistémica, realizada por jeringuilla hipodérmica, vía intramuscular, vía intravenosa.

Los códigos apropiados para esta terapia son:

- 99.23. Inyección de esteroide.

- 99.29. Inyección o infusión de otra sustancia terapéutica o profiláctica.

En este código se pueden registrar la inyección de analgésicos, incluidos opioides, la infusión intravenosa de lidocaína y otros anestésicos, test intravenoso con lidocaína o infusión de bifosfonatos.

- IAP.

- Inyección (dentro de) (hipodérmica) (intramuscular) (intravenosa) (de acción local o generalizada).

- Agente terapéutico NCOC. 99.29.

- Esteroide NCOC. 99.23.

En ocasiones se utilizan bombas de infusión, que son sistemas que facilitan la administración de medicación por vía subcutánea o intravenosa, manteniendo una dosis y un flujo constantes. Una bomba de infusión externa consta de un cassette que se carga con la dosis de medicación establecida; se programa con los parámetros adecuados y se conecta al catéter correspondiente. El sistema PCA permite al paciente autoadministrarse dosis extras de medicación pulsando un botón del dispositivo, dentro de unos parámetros prefijados. No existe ningún código en la CIE9MC para codificar las bombas externas (PCA) (analgesia controlada por el paciente), por lo que se codifica solo la inyección o infusión vía parenteral.

\section{Infiltraciones}

Consiste en la inyección local de un medicamento con el fin de reducir la inflamación y/o el dolor en la zona a tratar. Entre los fármacos más utilizados están corticoides, anestésicos locales, ácido hialurónico o toxina botulínica.

Técnica. Tras la identificación del punto de punción se introduce la aguja para alcanzar la zona de inyección. La infiltración se puede realizar a diversos niveles anatómicos: articulaciones, bursa sinovial, fascia, ligamentos, tendones, músculos, puntos gatillo.

Codificación. Existen códigos específicos según la estructura a infiltrar, no influyendo el fármaco empleado.
- 81.92. Inyección de sustancia terapéutica en articulación o ligamento.

- 83.96. Inyección de sustancia terapéutica en bolsa sinovial.

- 82.94. Inyección de sustancia terapéutica en bolsa sinovial de mano.

- 83.97. Inyección de sustancia terapéutica en tendón.

- 82.95. Inyección de sustancia terapéutica en tendón de mano.

- 83.98. Otra inyección de sustancia terapéutica de acción local en otro tejido blando. Excluye inyección subcutánea o intramuscular (99.29), como sería el caso de la toxina botulínica que se inyecta en el músculo.

- 82.96. Otra inyección de sustancia terapéutica de acción local en tejido blando de mano. Excluye inyección subcutánea o intramuscular (99.29).

- 76.96. Inyección de sustancia terapéutica en articulación temporomandibular (p. ej. ácido hialurónico).

- IAP.

- Inyección (dentro de) (hipodérmica) (intramuscular) (intravenosa) (de acción local o generalizada).

- Articulación (agente terapéutico) 81.92.

- Temporomandibular 76.96.

- Bolsa sinovial (agente terapéutico) 83.96.

- Mano 82.94.

- Fascia 83.96.

- Mano 82.96.

- Ligamento (articulación) (sustancia terapéutica) 81.92.

- Introducción.

- Sustancia terapéutica (de acción local o generalizada) NCOC 99.29.

- Articulación 81.92.

- Temporomandibular 76.96.

\section{Tratamiento con radioisótopos}

Para el tratamiento del dolor óseo metastásico se pueden utilizar radioisótopos, como el samario 153 o el estroncio 89.

Técnica. Consiste en la inyección intravenosa del isótopo bajo medidas de radioprotección y con control gammagráfico.

- IAP.

- Inyección (dentro de) (hipodérmica) (intramuscular) (intravenosa) (de acción local o generalizada).

- Radioisótopos (intracavitaria) (intravenoso) 92.28.

\section{Acupuntura}

La acupuntura consiste en la inserción de finas agujas metálicas en lugares concretos del cuerpo humano llamados 
meridianos, con el fin de estimularlos o desbloquearlos. El objetivo es liberar endorfinas y otros neurotransmisores para reducir la inflamación y disminuir el dolor.

Técnica. Dependiendo del diagnóstico se seleccionan las agujas, los puntos de acupuntura y el tiempo que deben permanecer insertadas las agujas. Las inserciones se realizan siguiendo un orden establecido de arriba hacia abajo, de la izquierda hacia la derecha, de adelante hacia atrás y penetrando la aguja más o menos profundamente según la enfermedad.

- IAP.

- Acupuntura. 99.92.

- Con moxa ardiente. 93.35.

\section{Procedimientos invasivos y quirúrgicos}

\section{Bloqueos farmacológicos del sistema nervioso}

El bloqueo nervioso consiste en la introducción de una sustancia (anestésico local, corticoide o neurolítico) en la proximidad de los nervios con objeto de interrumpir la conducción nerviosa.

Se pueden realizar a tres niveles:

- Sistema nervioso periférico.

- Sistema nervioso central.

- Sistema nervioso simpático.

Bloqueo nervioso periférico de plexo, tronco o nervio

Consiste en la denervación de las áreas dolorosas actuando sobre el sistema nervioso periférico. Este sistema está formado por: a) los nervios que emergen del sistema nervioso central (cerebro y médula espinal) y recorren todo el cuerpo y b) los ganglios nerviosos que se encuentran en el trayecto de los nervios. Del tronco cerebral surgen los nervios llamados pares craneales. De la médula espinal salen 31 pares de nervios espinales que se conectan entre sí, dando lugar a complejas redes nerviosas, llamadas plexos nerviosos. De cada uno de estos plexos resultan los troncos nerviosos que se extienden dando lugar a nervios periféricos.

Técnica. Consiste en inyectar un medicamento (anestésico local, corticoide o neurolítico) en cualquiera de las estructuras del sistema nervioso periférico (plexo, tronco o nervio) para interrumpir la conducción nerviosa con fines diagnósticos, pronósticos, terapéuticos o profilácticos. Para colocar la aguja en el lugar exacto a veces se utilizan estimuladores de nervios periféricos o ecografía y una vez localizado el punto de inyección se infiltra la dosis adecuada de medicación.

Codificación. Los bloqueos nerviosos periféricos se encuentran codificados en la subcategoría 04.8 Inyección dentro de nervio periférico:
- 04.80. Inyección de nervio periférico, no especificada de otra manera.

- 04.81. Inyección de anestésico dentro del nervio periférico con fines analgésicos, en este código están incluidos los siguientes tipos de bloqueos:

- Bloqueo del ganglio de Gasser.

- Bloqueo nervio intercostal.

- Bloqueo del nervio trigémino.

- Bloqueo nervioso periférico.

- Bloqueo nervioso periférico.

- Bloqueo de nervios craneales.

- Bloqueo nervioso de plexos.

- Bloqueo troncular.

- Bloqueo facetario (del ramo medial).

- Bloqueo sacroilíaco.

- Bloqueo coxofemoral.

- Otros bloqueos NCOC.

El bloqueo por agente neurolítico se codifica con el código 04.2, Destrucción de nervios craneales y periféricos.

- IAP.

- Bloqueo.

- Nervio (craneal) (periférico) NCOC. 04.81.

- Intercostal. 04.81.

- Periférico. 04.81.

- Trigémino. 04.81.

- Inyección (dentro de) (hipodérmica) (intramuscular) (intravenosa) (de acción local o generalizada).

- Nervio (craneal) (periférico). 04.80.

- Agente NCOC. 04.89.

- Alcohol. 04.2.

- Anestésico para analgesia. 04.81.

Si se trata de un bloqueo nervioso continuo, se codificará además la implantación del catéter correspondiente (Ver apartado 3.2.).

Bloqueo central espinal

Consiste en la denervación del neuroeje por vía intrarraquídea inyectando medicación bien en el espacio epidural, subaracnoideo o subdural.

Técnica. Consiste en inyectar un medicamento (anestésico local, corticoide o neurolítico) en el espacio epidural, subaracnoideo o subdural para interrumpir la conducción nerviosa con fines diagnósticos, pronósticos, terapéuticos o profilácticos.

El bloqueo espinal más usado en dolor es el bloqueo epidural que consiste en introducir un medicamento, anestésico local y/o corticoide, en el espacio epidural con fines analgésicos. Con una aguja de Tuhoy y mediante la técnica de la gota suspendida de Gutiérrez o mediante la técnica de pérdida de resistencia se localiza el espacio epidural lumbar, dorsal o cervical, donde se introduce la medicación.

Codificación. En este apartado se incluyen las siguientes técnicas: 
- Bloqueo epidural cervical, dorsal, lumbar o caudal.

- Bloqueo intratecal (intradural o subaracnoideo) cervical, dorsal o lumbar.

- Bloqueo espinal diferencial.

- IAP.

- Inyección (dentro de) (hipodérmica) (intramuscular) (intravenosa) (de acción local o generalizada)

- Espinal (canal) NCOC 03.92.

- Agente.

- Anestésico para analgesia 03.91.

- Destructivo NCOC 03.8.

- Neurolítico NCOC 03.8.

- Alcohol 03.8.

- Esteroide 03.92.

- Fenol 03.8.

Se excluye la inyección de anestésico en el conducto espinal para la anestesia operatoria, debiendo omitirse el código.

\section{Bloqueo nervioso simpático}

Consiste en la denervación y/o interrupción de las vías del sistema nervioso autónomo, que es en gran parte responsable de la nocicepción visceral. Las vías simpáticas pueden ser interrumpidas en diversos sitios: espacio subaracnoideo, espacio epidural, regiones paravertebral y prevertebral, los nervios periféricos y las terminaciones de los axones postganglionares.

Técnica. Consiste en inyectar medicación (anestésico local, corticoide o neurolítico) en cualquiera de las estructuras del sistema nervioso simpático para interrumpir la conducción nerviosa con fines diagnósticos, pronósticos, terapéuticos o profilácticos.

Codificación. El bloqueo simpático se codifica en la subcategoría 05.3, Inyección en nervio o ganglio simpático:

- 05.31 Inyección de anestésico en nervio simpático con fines analgésicos incluye el bloqueo simpático cérvico-torácico o del ganglio estrellado, el bloqueo simpático torácico-paravertebral, el bloqueo simpático lumbar y el bloqueo simpático hipogástrico.

- 05.32 Inyección de agente neurolítico en ganglio simpático, incluye el bloqueo neurolítico paravertebral simpático, el bloqueo neurolítico del plexo celíaco, y el bloqueo neurolítico del plexo hipogástrico superior.

- Si estos tratamientos se realizan con un bloqueo simpático continuo, se codifica además la implantación del catéter correspondiente (ver apartado 3.2.)

- IAP.

- Inyección (dentro de) (hipodérmica) (intramuscular) (intravenosa) (de acción local o generalizada)

- Nervio.

- Simpático. 05.39.

- Agente neurolítico. 05.32.
- Alcohol. 05.32.

- Anestésico para analgesia. 05.31.

- Fenol. 05.32.

- Ganglio.

- Simpático. 05.39.

- Estrellado paravertebral. 05.39.

- Destrucción.

- Nervio.

- Simpático, por inyección de agente neurolítico. 05.32 .

Infusión de medicación a través de catéter espinal

Inserción del catéter espinal

Consiste en colocar en el canal espinal (espacio epidural, subaracnoideo o subdural) un catéter largo, flexible y radiopaco a través del cual se introduce medicación bien con una jeringa, bien conectándole a una bomba de infusión externa, a un reservorio o a una bomba de infusión interna.

Técnica. Se localiza el espacio correspondiente con una aguja de Tuhoy y a través de ella se introduce el catéter. Una vez colocado el catéter en el sitio deseado se retira el fiador metálico y la aguja de Tuhoy.

Codificación. Se debe codificar además cualquier implantación o bomba de perfusión (código 86.06).

- IAP.

- Inserción.

- Catéter canal espinal, espacio (epidural) (subaracnoideo) (subdural) para infusión (continua o intermitente) de sustancia terapéutica o paliativa 03.90.

Tunelización del catéter

Es un procedimiento para mejorar la fijación del catéter, introduciéndolo en el tejido celular subcutáneo.

Técnica. Se pasa la aguja haciendo un túnel bajo el tejido subcutáneo adyacente y, a través de él, se pasa el catéter.

Codificación. El código correspondiente es 86.99 Otras operaciones sobre piel y tejido subcutáneo.

- IAP

- Túnel, subcutáneo (antetorácico) 42.86.

- Cable conductor del generador de impulsos 86.99. - Con procedimiento inicial - omitir código.

Infusión de medicación a través de catéter espinal

Es la administración intrarraquídea de medicación (cloruro mórfico, anestésicos, otros) a través de un catéter espinal. 
Técnica. Se puede realizar mediante:

- Inyección directa de la medicación, con jeringuilla, a través del catéter.

- Una bomba de infusión externa que se conecta al catéter.

- La implantación de un reservorio subcutáneo, que se conecta al catéter espinal, y se compone de una cápsula cilíndrica con una membrana de silicona que permite el acceso a través de punción cutánea para la inyección o infusión de medicación.

- La implantación de una bomba de infusión interna, conectada al catéter espinal (Ver punto 3.3).

Codificación:

- 03.91 Inyección de anestésico en el conducto espinal para analgesia.

- 03.92 Inyección de otro agente en canal espinal.

No existe ningún código en la CIE9MC para la bomba de infusión externa ni para el reservorio subcutáneo cuando se conecta a un catéter situado en el canal espinal, como sí tienen los reservorios conectados a una vía vascular. Es preciso codificar también cualquier cateterización asociada (03.90).

\section{Bomba de infusión interna}

Implante de bomba de infusión interna

La bomba de infusión interna se implanta en el tejido celular subcutáneo y se conecta con el canal espinal a través de un catéter tunelizado. Pueden ser de flujo variable programable por telemetría o de flujo fijo. Son de titanio y en su interior hay una cavidad que se recarga con medicación, a través de un botón de silicona accesible por medio de punción cutánea. La medicación se va liberando, a un flujo continuo y prefijado, a través del catéter conectado con el canal espinal.

Técnica. Mediante punción lumbar con una aguja de Tuhoy se introduce un catéter en el espacio intradural y se tuneliza hasta la línea media axilar. Posteriormente se implanta la bomba en un bolsillo subcutáneo realizado en el abdomen, conectada con otro catéter que también se tuneliza. Finalmente ambos catéteres se conectan entre sí y queda establecido el flujo entre la bomba y el espacio intradural.

Codificación. El código apropiado es 86.06 Inserción de bomba de infusión totalmente implantable. Se debe codificar además cualquier cateterización asociada.

- IAP.

- Implante.

- Bomba de infusión 86.06.

- Inserción.

- Infusión, bomba de 86.06.
Relleno y programación de bomba de flujo fijo o variable

Antes de que la medicación que contiene la bomba se termine, hay que recargarla y revisar su funcionamiento, bien midiendo unos parámetros (flujo fijo), bien conectándola a un ordenador por telemetría (flujo variable).

Técnica. Con el paciente en decúbito supino y a través de la piel, se palpa y pincha con una aguja especial el septum (botón de silicona) de la bomba, procediéndose a extraer la medicación sobrante y a recargar de nuevo el sistema. Las bombas de flujo variable llevan una antena para programar la dosis de infusión con un ordenador desde el exterior.

Codificación. Incluye la administración de corticoides, cloruro mórfico, baclofeno, zicotidine.

Los códigos correspondientes son:

- 03.91 Inyección de anestésico en el conducto espinal para analgesia.

- 03.92 Inyección de otro agente en canal espinal.

Explante de bomba interna

Consiste en la retirada de la bomba de forma definitiva o para sustituirla por otra bomba de infusión.

Técnica. Se realiza una incisión para acceder al bolsillo abdominal, se libera la bomba de los puntos de sujeción y de la conexión al catéter y se procede a su extracción.

Codificación. El código apropiado es 86.05 Incisión con extracción de cuerpo extraño o dispositivo de piel y tejido celular subcutáneo.

\section{Retirada de catéter}

Consiste en la retirada parcial o total del catéter, bien por estar deteriorado, bien porque ya no es necesario.

Técnica. Dependiendo de la porción a explantar, se realizan incisiones en las zonas de conexión entre catéteres y/o en la conexión bomba-catéter.

Codificación. Se codifica como 03.99 Otras operaciones sobre la médula espinal y estructuras del conducto espinal.

\section{Recambio de pila}

Cuando se agota la pila que lleva la bomba de infusión interna y se realiza un ingreso para cambiarla, el código principal será un código de colocación y ajuste de dispositivo (V53.09).

\section{Radiofrecuencia sobre estructuras nerviosas}

La radiofrecuencia es una técnica que consiste en producir un bloqueo nervioso, empleando corrientes eléctricas 
de alta frecuencia, lo que permite, controlando los parámetros eléctricos y las características del electrodo, crear una lesión controlada, circunscrita y predecible. El equipo se compone de un generador de radiofrecuencia y un fino electrodo. La destrucción del tejido nervioso ocurre por el calor que se genera en la punta del electrodo.

Se puede realizar a diversos niveles: pares craneales, raíces nerviosas, nervios periféricos, entre otros.

Técnica. Se introduce un fino electrodo en el lugar deseado con la ayuda de técnicas radiológicas. Al aplicársele corriente eléctrica se calienta, destruyendo por quemadura las fibras nerviosas que trasmiten la sensación dolorosa.

Codificación. El código varía según la estructura donde se produce la lesión por radiofrecuencia. Así cabe destacar:

- Gangliólisis por radiofrecuencia percutánea del trigémino 04.02.

- Rizotomía percutánea por radiofrecuencia 03.1.

- Denervación percutánea de facetas por radiofrecuencia 03.96.

- Neuroablación por radiofrecuencia 04.2.

- IAP.

- Destrucción.

- Lesión

- Nervio (craneal) (periférico) (por radiofrecuencia) 04.2.

- Denervación.

- Faceta, percutánea (radiofrecuencia) 03.96.

- Ganglionotomía, trigémino (radiofrecuencia) 04.02.

- Neuroablación.

- Radiofrecuencia 04.2.

- Rizotomía (radiofrecuencia) (espinal) 03.1

Los bloqueos por radiofrecuencia que no se encuentran con entrada en el índice alfabético, se codificaran como los bloqueos nerviosos (ver punto 3.1).

\section{Electroestimulación o neuroestimulación}

La neuroestimulación se utiliza para el tratamiento de diferentes síndromes que cursan con dolor crónico. Puede realizarse en distintas localizaciones: medular, intracraneal o periférica. Los neuroestimuladores se componen de un generador de pulsos y de uno o más electrodos.

Implante del generador interno o neuroestimulador

Tras un periodo de prueba, si el resultado es favorable, se procede a internalizar el sistema, colocando el neuroestimulador subcutáneo.

Técnica. Se realiza quirúrgicamente un bolsillo subcutáneo en la pared abdominal y se implanta un neuroestimulador programable mediante un sistema de telemetría. Por tunelización se conecta a los electrodos.
TABLA I. BOMBA DE INFUSIÓN INTERNA

\begin{tabular}{ll}
\hline Implante & $86.06+03.90$ \\
& $\begin{array}{l}\text { 03.91 Inyección de anestésico } \\
\text { en el conducto espinal para } \\
\text { analgesia }\end{array}$ \\
Relleno y & O \\
programación & $\begin{array}{l}\text { 03.92 Inyección de otro agente } \\
\text { en canal espinal }\end{array}$ \\
Explante de bomba & $\begin{array}{l}\text { 86.05 Incisión con extracción de } \\
\text { cuerpo extraño o dispositivo de } \\
\text { piel y tejido celular subcutáneo } \\
\text { interna }\end{array}$ \\
Retirada de catéter & $\begin{array}{l}\text { 03.99 Otras operaciones sobre la } \\
\text { médula espinal y estructuras del } \\
\text { conducto espinal }\end{array}$ \\
\hline
\end{tabular}

Codificación. El implante del generador se codifica con los mismos códigos con independencia de si la neuroestimulación es medular, intracraneal o periférica. El código varía según el número de electrodos que se utilicen y si el neuroestimulador es o no recargable (86.94-86.98). La retirada del neuroestimulador con sustitución simultánea del mismo tiene la misma codificación que el implante inicial. Es preciso codificar además la implantación de los electrodos asociados (02.93 intracraneal, 03.93 medular, 04.92 periférico).

- 86.94. Inserción o sustitución de neuroestimulador generador de pulsos de un solo electrodo, no especificado como recargable.

- 86.95. Inserción o sustitución de neuroestimulador generador de pulsos de doble electrodo, no especificado como recargable.

- 86.96. Inserción o sustitución de otro neuroestimulador generador de pulsos.

- 86.97. Inserción o sustitución de neuroestimulador generador de pulsos recargable de electrodo único.

- 86.98. Inserción o sustitución de neuroestimulador generador de pulsos recargable de doble electrodo.

- IAP.

- Implante.

- Neuroestimulador.

- Generador de pulso 86.96.

- Disposición dual 86.95.

- Recargable 86.98.

- Disposición sencilla 86.94.

- Recargable 86.97.

Es preciso codificar además la implantación de los electrodos asociados $(02.93,03.93,04.92)$.

- IAP.

- Implante.

- Neuroestimulador.

- Electrodo. 
- Cerebro 02.93.

- Intracraneal 02.93.

- Médula espinal 03.93.

- Nervio periférico 04.92.

- Nervio sacro 04.92.

Programación del neuroestimulador

Consiste en establecer, desde un ordenador externo, por telemetría, los parámetros adecuados para realizar la electroestimulación deseada.

Técnica. Se programan los parámetros en el ordenador externo. El paciente dispone de un mando externo para conectar y desconectar el sistema y para modificar el voltaje de la corriente entre los límites programados por telemetría.

Codificación. No existe código para la programación del neuroestimulador.

\section{Extracción de neuroestimulador}

Consiste en la retirada del neuroestimulador; puede ser definitiva o para su sustitución por otro sistema.

Técnica. Se realiza una incisión sobre el bolsillo de la pared abdominal para acceder al generador, se liberan los puntos de fijación y la conexión con los electrodos y se procede a su extracción o recambio.

Codificación. La retirada del neuroestimulador con sustitución simultánea del mismo tiene la misma codificación que el implante inicial (86.94-86.98). Para el explante definitivo se utiliza el código 86.05 Incisión con extracción de cuerpo extraño o dispositivo de piel y tejido subcutáneo independientemente de si tiene uno o dos electrodos asociados.

- IAP.

- Extracción.

- Neuroestimulador.

- Generador de pulso (disposición sencilla, disposición dual) 86.05.

- Con sustitución simultánea 86.96.

- Disposición dual 86.95.

- Disposición sencilla 86.94

- Electrodo doble 86.95

- Recargable 86.98

- Electrodo único 86.94

- Recargable 86.97

Implante de electrodos

Consiste en la colocación de uno o varios electrodos en el espacio epidural, cerebro o zona deseada.
Extracción de electrodos

Es la retirada de los electrodos bien porque se han dejado de utilizar, bien para sustituirlo/s por otro/s.

Neuroestimulación medular

La neuroestimulación medular se utiliza para obtener un efecto analgésico mediante la estimulación eléctrica de determinadas zonas medulares (cordones posteriores). La estimulación medular bloquearía la transmisión del impulso nervioso mediado por las fibras que conducen el dolor (C y A-delta), debido a la estimulación de fibras de conducción rápida, no portadoras de información dolorosa, inhibiendo así la transmisión del dolor, creando parestesias en la zona dolorosa. Los neuroestimuladores se componen fundamentalmente de un generador de pulsos y de uno o más electrodos.

Técnica. A través de una aguja de Tuhoy colocada en el espacio epidural se introducen unos electrodos que se hacen progresar en dirección cefálica hasta alcanzar la zona de predominio del dolor. Esta se localiza porque el electrodo está conectado a un estimulador externo y el paciente va describiendo sus sensaciones. Finalmente se tuneliza la conexión externa temporal y se procede a realizar un programa de estimulación durante varias horas al día y en distintas situaciones de actividad (caminar, sentarse, subir escaleras, etc.).

Codificación. El código apropiado es 03.93 Colocación o sustitución de cable(s) de neuroestimulador medular. Hay que tener en cuenta que la extracción del electrodo con la sustitución simultánea del mismo tiene el mismo código.

Implante de electrodo espinal

Consiste en la colocación de uno o varios electrodos en el espacio epidural

- IAP.

- Implante.

- Electrodos.

- Espina dorsal 03.93.

- Neuroestimulador.

- Electrodos.

- Médula espinal 03.93.

Extracción del electrodo espinal

Es la retirada del electrodo bien porque se ha dejado de utilizar, bien para sustituirlo por otro.

Técnica. Se localizan los puntos de conexión del electrodo con el neuroestimulador y se procede a su extracción o sustitución. 
Codificación. Tiene entrada directa por el índice como:

- IAP.

- Extracción.

- Electrodos.

- espinales 03.94.

- Con sustitución simultánea 03.93.

- Neuroestimulador.

- Electrodos.

- Medular 03.94.

- Con sustitución simultánea 03.93.

\section{Neuroestimulación intracraneal}

La estimulación cerebral profunda trabaja mediante la estimulación eléctrica de estructuras diana en el cerebro relacionadas con la transmisión del dolor.

Técnica. Se implanta un electrodo quirúrgicamente en el cerebro y se conecta a un neuroestimulador implantado cerca de la clavícula, mediante una extensión tunelizada por debajo de la piel. El estímulo eléctrico se puede ajustar de manera no invasiva hasta alcanzar las necesidades individuales de cada paciente.

Codificación. Se codifican las distintas etapas del proceso:

- Implante de electrodo intracraneal: 02.93. Incluye la extracción con sustitución simultánea.

- Implante de neuroestimulador (ver punto implante de generador).

- Extracción de neuroestimulador (ver extracción de neuroestimulador).

- Retirada de electrodo intracraneal: 01.22. Excluye: extracción con reemplazamiento simultáneo 02.93.

- IAP.

- Implante.

- Electrodo.

- Cerebro 02.93.

- Intracraneales 02.93.

- Extracción.

- Electrodo.

- Cerebro 01.22.

Intracraneales 01.22.

- Con sustitución simultánea 02.93.

\section{Neuroestimulación periférica}

Consiste en el implante de electrodos a nivel subcutáneo, radicular o de nervios periféricos, conectados a un neuroestimulador. Para localizar correctamente la zona del implante se utiliza un estimulador de nervios periféricos.

Técnica. Tras implantar el electrodo en la zona deseada, se procede a su tunelización y conexión con el neuroestimulador.
Codificación Se codifican las distintas etapas del proceso:

- Implante de electrodo periférico: 04.92. Incluye la extracción con sustitución simultánea.

- Implante de neuroestimulador (ver implante neuroestimulador).

- Extracción de neuroestimulador (ver extracción neuroestimulador).

- Retirada de electrodo periférico: 04.93. Excluye la extracción con reemplazamiento simultáneo 04.92.

- IAP.

- Implante.

- Electrodo.

- Nervio periférico 04.92.

- Extracción.

- Electrodo.

- Nervio periférico 04.93.

- Con sustitución simultánea 04.92.

\section{Otras técnicas invasivas}

Técnicas de punción muscular profunda para tratamiento con toxina botulínica

Consiste en la infiltración de la musculatura profunda, como el músculo psoas, cuadrado lumbar, piriforme, etc., con toxina botulínica. La toxina botulínica es una neurotoxina que interfiere la contracción muscular, produciendo una relajación de la contractura muscular, con reducción del dolor.

Técnica. Mediante control radiológico se localiza el músculo a tratar y se inyecta mediante la aguja adecuada el fármaco.

Codificación. Tiene entrada por el índice como:

- IAP.

- Inyección (intramuscular).

- Agente terapéutico 99.29.

\section{Vertebroplastia y cifoplastia}

La vertebroplastia y la cifoplastia se usan para tratar el dolor causado por la fractura-aplastamiento de los cuerpos vertebrales, debida generalmente a osteoporosis o neoplasias.

Técnica. Consiste en inyectar una mezcla de cemento especial a través de una aguja hueca (trocar óseo) dentro del hueso fracturado. En la cifoplastia, se inserta primero un balón a través de la aguja en un intento de aumentar la altura del cuerpo vertebral. El cemento se inyecta en el vacío que queda tras la retirada del globo.

Codificación. Tiene entrada por el índice como:

- IAP.

- Vertebroplastia percutánea 81.65.

- Cifoplastia 81.66. 


\section{Ozonoterapia}

La ozonoterapia es la administración de ozono mezclado con oxígeno en el organismo con fines terapéuticos. La de mayor interés es la discolisis por ozono, que se basa en introducir en el disco una mezcla de oxígeno y ozono que actúa desecando el disco vertebral, con lo que comprime la hernia y la hace desaparecer. También se puede utilizar a nivel muscular.

Técnica. La discolisis consiste en localizar el disco a tratar, mediante medios radiológicos, e inyectar el ozono.

Codificación. La discolisis tiene entrada directa por el índice alfabético y el código apropiado es el 80.52.

\section{Epidurolisis o adhesiolisis}

Es un procedimiento que intenta eliminar las adherencias, las reacciones cicatriciales y fibróticas postquirúrgicas.

Técnica. Se puede realizar introduciendo un catéter junto a la raíz afectada a través del que se infunde metilprednisolona y suero hipertónico, o bien por radiofrecuencia.

Codificación. Se utiliza el código 03.6 Lisis de adherencias de médula espinal y raíces de nervios espinales. Se debe codificar además cualquier aplicación o administración de una sustancia antiadherencia (99.77).

- IAP.

- Adhesiolisis - véase además Lisis, adeherencias.

- Lisis.

- Adherencias.

- Espinales (médula) (meninges) (raíces de nervios) 03.6.

- Meninges (espinales) 03.6.

\section{Epiduroscopia}

Método endoscópico para visualizar el espacio epidural, útil en el diagnóstico y tratamiento de síndromes dolorosos de la médula espinal.

Técnica. Se introduce en el espacio epidural un endoscopio flexible y direccionable o un epiduroscopio para visualizar y tratar las estructuras lesionadas.

Codificación. El código adecuado es 03.39 Otros procedimientos diagnósticos sobre la médula espinal y estructuras del conducto espinal.

\section{Discografía}

La discografía o discograma es una herramienta de diagnóstico que se utiliza para determinar la integridad estructural de los discos intervertebrales.

Técnica. Se realiza una punción percutánea y bajo radioscopia se inyecta contraste en el disco intervertebral a estudio.

Codificación. Tiene entrada por el índice como:

- IAP.

- Discograma 87.21.

CORRESPONDENCIA:

Lorenzana Vicente Fatela

Hospital Universitario 12 de Octubre

Avda. Córdoba, s/n

28041 Madrid

Teléfono: 913908300

\section{BIBLIOGRAFÍA}

1. Clasificación Internacional de Enfermedades. 9. ${ }^{a}$ revisión. Modificación clínica, 7. a ed. Madrid: Ministerio de Sanidad y Política social. Secretaría General Técnica; Enero 2010.

2. ICD-9-CM Official Guidelines for Coding and Reporting. Effective October 1, 2009.

3. Manual del usuario. Normativa de Codificación. Ministerio de Sanidad y Consumo. 4. ${ }^{\text {a }}$ edición. 1997.

4. De la Riva I, Vara Lorenzo A, et al. Codificación Clínica con la CIE-9. Monográfico de Traumatología. Boletín n. ${ }^{\circ} 14$ año V. Octubre 1999.

5. Bonica JJ. The need of taxonomy. Pain 1979;6:247-52.

6. Bonica JJ. Definitions and taxonomy of pain. En: Bonica JJ (editor). The management of pain. 2. ${ }^{\mathrm{a}}$ ed. Philadelphia: Lea \& Febriger; 1990. p. 18-27.

7. Turk DC, Okifuji A. Terminología y taxonomía del dolor. En: Loeser JD (editor). Bonica. Terapéutica del Dolor. 3. ${ }^{a}$ ed. Mexico D.F.: McGraw-Hill Interamericana; 2003. p. 19-29.

8. Merskey H. The definition of pain. Enr J Psychiatry 1997; 6:153-9.

9. Turk DC, Rudy TE. The robustness of an empirically derived taxonomy of chronic pain patients. Pain 1990;43:27-35.

10. Vicente Fatela L, Acedo Gutiérrez MS, et al. Codificación del dolor crónico con la clasificación Internacional de enfermedades 9. a revisión Modificación clínica (CIE-9-MC). Rev Soc Esp Dolor 2006;14:95-103.

11. De la Calle JL, Abejón D, et al y Panel de expertos de la Sociedad Madrileña del Dolor. Estándares de calidad asistencial y catálogo de procedimientos de las Unidades de dolor crónico. Rev Soc Esp Dolor 2010;17(2):114-33.

12. Ministerio de Sanidad, Política Social e Igualdad. Estándares y recomendaciones en las Unidades de Dolor. En prensa 2011. 